\title{
Effect of Complementary Medicine on Pain Relief and Wound Healing after Cesarean Section: A Systematic Review
}

\author{
Azin Niazi ${ }^{1}$, Maryam Moradi ${ }^{2} *$ Vahid Reza Askari $^{3}$, Neda Sharifi ${ }^{4}$ \\ ${ }^{1}$ School of Nursing and Midwifery, Mashhad University of Medical Sciences, Mashhad, Iran \\ ${ }^{2}$ Nursing and Midwifery Care Research Center, Mashhad University of Medical Sciences, Mashhad, Iran \\ ${ }^{3}$ Pharmacological Research Center of Medicinal Plants, Mashhad University of Medical Sciences, Mashhad, Iran \\ ${ }^{4}$ Department of Midwifery, Mashhad Branch, Islamic Azad University, Mashhad, Iran
}

Received March 1, 2020

Reviewed April 28, 2021

Accepted May 18, 2021

*Corresponding Author Maryam Moradi

Nursing and Midwifery Care Research Center, Mashhad University of Medical Sciences, Mashhad, Iran

Tel: +05138591511

E-mail: moradim@mums.ac.ir
Objectives: Cesarean sections are one of the common surgical procedures around the world. Management of cesarean section side effects, including pain, hematoma, delayed wound healing, is of particular importance in maintaining maternal health and ability to care for the baby. The tendency to use complementary medicine strategies is on the rise because of the easy treatment with low side effects. The purpose of this study was to systematically review the efficacy and safety of clinical trials performed in Iran and worldwide on the effect of complementary medicine on pain relief and wound healing after cesarean section.

Methods: PRISMA checklist was followed to prepare the report of this systematic review. The search process was carried out on databases on databases of Magiran, SID, Iran Medex, Scopus, Pub Med, Science direct, Medline and Cochrane library using keywords of cesarean, pain, wound healing, Herbal medicine, acupressure, massage, complementary medicine and their Persian equivalent and all possible combinations, from inception until February 2020. We used the Jadad scale to assess the quality of the searched articles. According to the Jadad scale, the articles with a score of at least 3 were included in the study.

Results: Finally, 28 clinical trials (with a sample size of 3,245) scored at least 3 on the Jadad scale were included into the analysis. This article reviewed 13 articles on medicinal herbs, 4 articles on massage, 1 article on reflexology, 2 articles on acupressure.

Conclusion: According to the present review, the use of medicinal herbs was the most common method of complementary medicine in pain relief and wound healing after cesarean section.

Keywords: wound, cesarean, pain, complementary, medicine, healing

\section{INTRODUCTION}

Cesarean sections are one of the common surgical procedures around the world, accounting for up to $60 \%$ of deliveries in some countries [1]. As the rate of cesarean section increases, the associated side effects, including hematoma, surgical site infection, incision site opening and pain, are on the rise [2]. Postoperative Cesarean sections pain can cause complications, including weakened immune system, increased myocardial oxygen consumption, reactive hypoglycemia leading to delayed wound healing, paralytic ileus and decreased respiratory function, through the development of neuroendocrine reflexes and increased sympathetic tone $[3,4]$. On the other hand, the presence of scar and the resulting pain interfere with the mother being in the proper position for breastfeeding and consequently effective breastfeeding, which causes delayed breastfeeding and 
reduces maternal mobility and delayed maternal-infant bonding $[5,6]$. Post-cesarean section wound also occurs despite the observation of correct surgical tips. However, surgical site infection, which is associated with hematoma, serous and incision site opening, is the most common cause of death following cesarean section surgery, leading to more hospitalizations and frequent referrals to the physician for discharge of secretions, debridement, wound healing, and high cost [2]. Management of pain and acceleration of wound healing after cesarean section are important for maternal and newborn care and breastfeeding. Many drugs used for this purpose, especially nonsteroidal anti-inflammatory drugs (NSAIDs) and opiates, have side effects including nausea, respiratory distress, gastrointestinal bleeding and itching [7]. Complementary and alternative medicines (CAMs) are diagnostic and therapeutic disciplines using herbal remedies, aromatherapy, massage therapy, vitamins, oral supplements, acupuncture, music therapy, relaxation and yoga, whose application is increasingly important in parallel with the increasing financial burden of health care in different countries [8]. Since the complementary medicine is particularly important for early pain relief and wound healing after cesarean section as an easy, available and inexpensive therapeutic approach with low side effects, the present study aimed to systematically review studies on complementary medicine in this area, and to summarize the outcomes of the clinical trials.

\section{MATERIALS AND METHODS}

In the present study, we used the Preferred Reporting Items for Systematic Reviews (PRISMA) checklist to provide materials ranging from analysis and interpretation, problem determination to study, and data collection [9]. the search process was performed to search the articles evaluating the effect of complementary medicine on pain relief and wound healing after cesarean section on databases of Magiran, SID, Iran Medex, Scopus, Pub Med, Science direct, Medline and Cochrane library using keywords of cesarean, pain, wound healing, treatment, herbal, herbal extract, Herbal medicine, acupressure, massage, complementary medicine, alternative medicine and their Persian equivalent and all possible combinations, from inception until February 2020, without any time constraints. Additionally, the references listed in all related articles were reviewed manually for finding further possible literature to maximize the search integrity.

Inclusion criteria for this structured review included clini- cal trials aiming at the evaluation of pain intensity and wound healing with appropriate tools. The study participants included women who used various complementary medicine techniques for pain relief and early wound healing after cesarean section. The outcomes were wound healing rate and reduced pain intensity. Irrelevant, duplicate, overview or letter to editor articles were excluded. If the full manuscript of the article was unavailable, the information in the abstract would be used and if the abstract did not provide essential information, the article would be excluded from the study. Fig. 1 shows the selection process of searched articles.

The Jadad scale was used to perform Quality assessment of searched articles, which reviews articles based on clinical trial design, randomization, blinding, follow-up and study methodology, with a minimum score of 1 and a maximum score of [10]. According to this scale, the articles with a score of at least 3 were enrolled in our study.

\section{RESULTS}

28 articles (with a sample size of 3,245 ) scored at least 3 on the Jadad scale were included into the analysis. This article reviewed 13 articles on medicinal herbs \{Mentha piperita, $(\mathrm{n}=1)$, Cuminum $(\mathrm{n}=1)$, Lavender $(\mathrm{n}=4)$, Calendula $(\mathrm{n}=1)$, Honey $(n=3)$, Dill $(n=2)$, Hypericum perforatum $(n=1)$, Grape Seeds $(n=1)$, Orange Blossom $(n=1)$, Aloe Vera $(n=2)$, Rosa $(\mathrm{n}=1)$, Chamomile $(\mathrm{n}=1)$, Flax Oil $(\mathrm{n}=1)$, Turmeric $(\mathrm{n}=1)\}$, 4 articles on massage, 1 article on reflexology, 2 articles on acupressure (Table 1).

\section{Mentha piperita}

Mentha piperita is a medicinally important plant in which belongs to the Family Lamiaceae. In addition, there are some reports of the uses of Mentha piperita extract for relief of dysmenorrhea and tension headaches [11]. In a study by Fazel et al. (2004), the intervention group received orally 40 drops of mint essential oil 20 minutes after serum withdrawal three times. The control group received placebo in this manner. The pain levels were assessed at the first, the second and the third 20 minutes and at 120 minutes after the intervention. The level of pain intensity in the intervention group was significantly decreased at the second 20 minutes, the third 20 minutes and at 120 minutes after the intervention compared to the control group $(\mathrm{p}<0.001)$ [12]. 

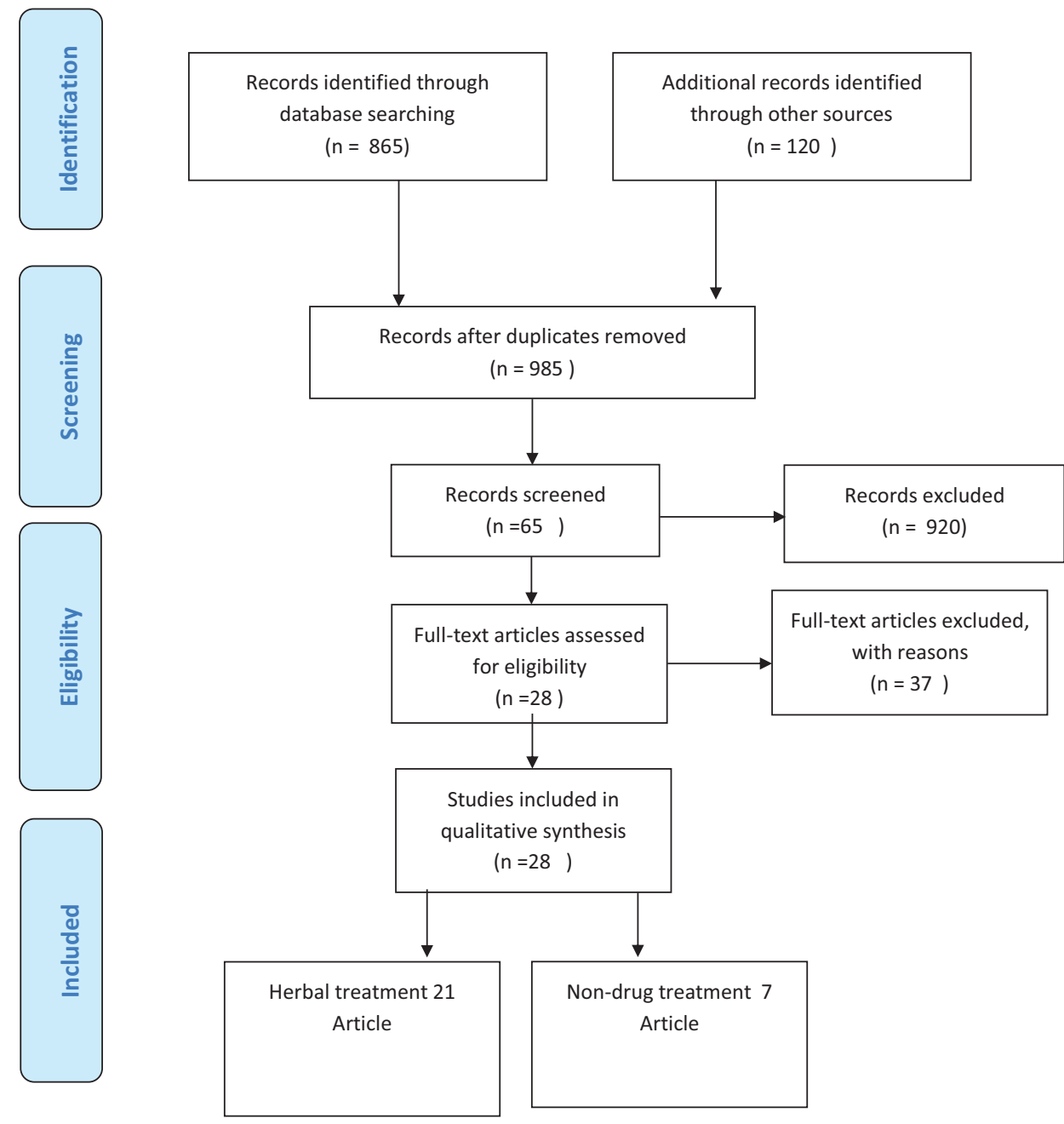

Figure 1. Study selection procedure (PRISMA flowchart).

\section{Cuminum cyminum}

Cuminum cyminum is a small annual and herbaceous plant belonging to the Apiaceae family. Cuminum has also been widely used in medicine to treat a variety of diseases including eupeptic, antispasmodic, astringent and used in the treatment of mild digestive disorders, flatulence, colic, dyspeptic headache and bloating [13]. In another study, Fazel et al. (2008), using a similar methodology, investigated the effect of oral cumin essential oil on pain intensity caused by bloating of cesarean section compared with placebo (a drop at a concentration of $0.1 \%$ cumin extract). Results showed that the pain intensity level was significantly decreased in the intervention group compared to the placebo at the second 20 minutes, the third 20 minutes and at 120 minutes after the intervention $(\mathrm{p}<0.001)$ [14].

\section{Lavender}

Lavandula angustifolia is a plant of Lamiaceae family, with many therapeutic properties such as antibacterial, antifungal, anxiolytic, sedative activities and anti-inflammatory for skin care [15]. In a study of Sobhani et al. (2002), two drops of lavender solution diluted with distilled water in a ratio of 0:1 were poured onto the palms of the intervention group and were advised to breathe for 3 minutes. The lavender essential oil and lavender perfume (without palliative effect) were administered in three stages (6-8 $\mathrm{h}$ after first stage), and the pain intensity was measured before and 30 minutes after each intervention. The results showed that the pain intensity in all three stages was significantly lower in the intervention group than in the control group $(\mathrm{p}<0.001)[16]$.

In a study of Ebrahimi Houshyar et al. (2015), the control group used a deactivated transcutaneous electrical nerve stimu- 


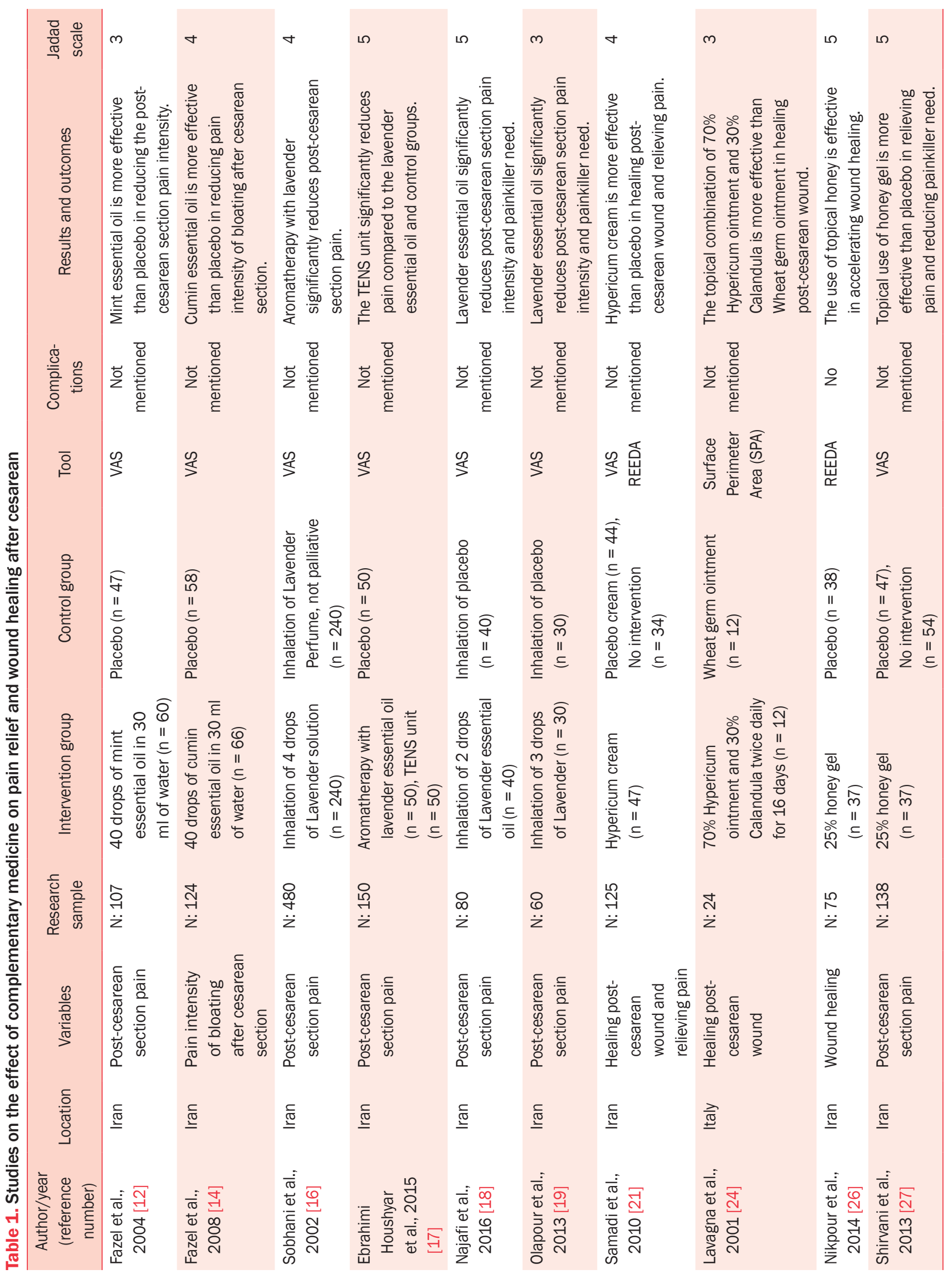




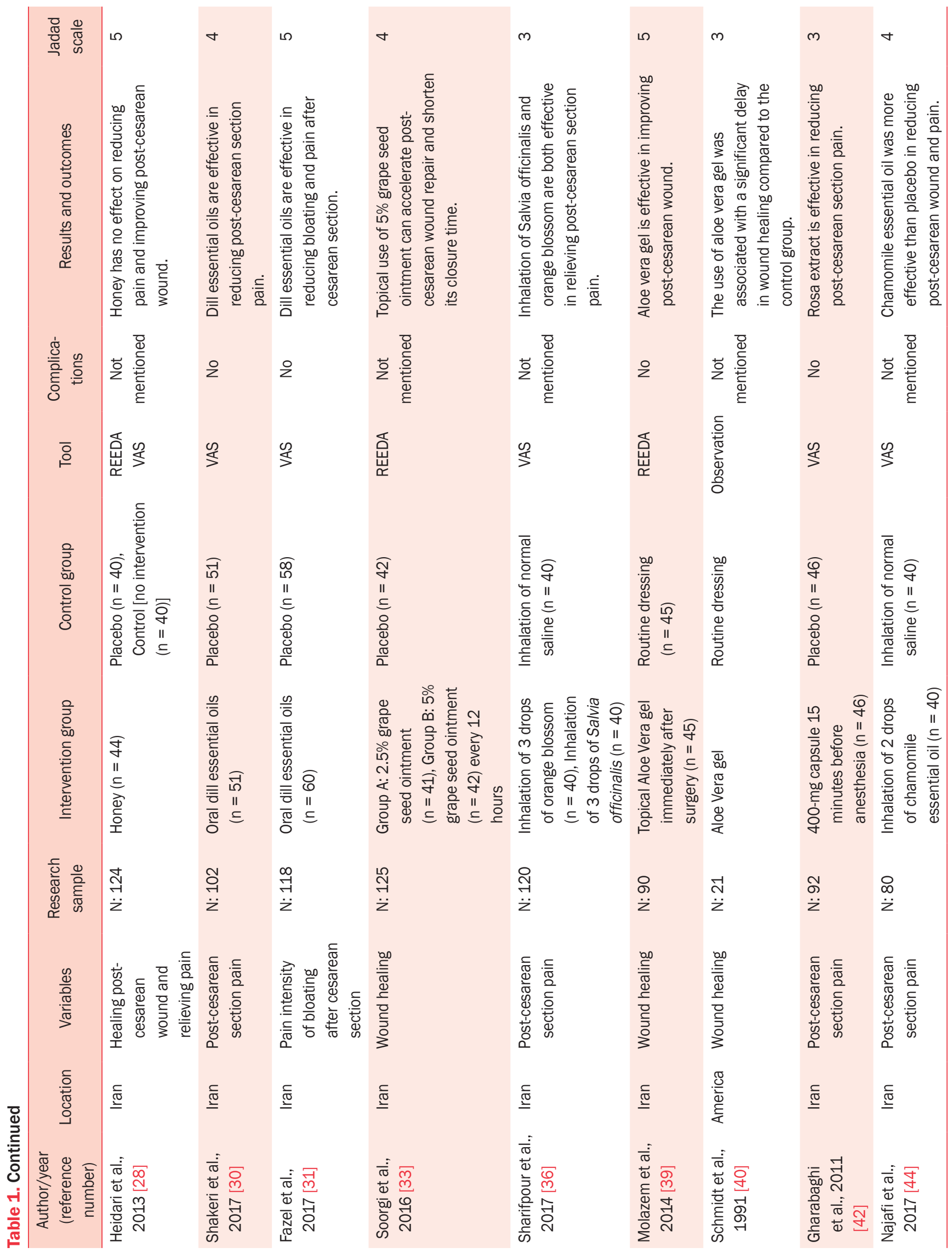




\begin{tabular}{|c|c|c|c|c|c|c|c|c|c|}
\hline$\frac{\pi}{\pi} \frac{0}{\pi} \frac{1}{\pi}$ & $\nabla$ & 10 & $\nabla$ & $1 \Omega$ & 10 & \llcorner & L & $\checkmark$ & $m$ \\
\hline 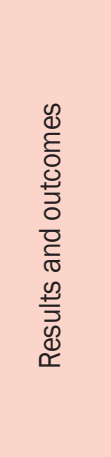 & 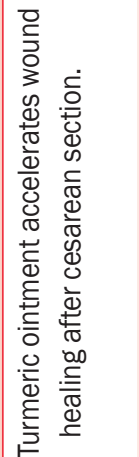 & 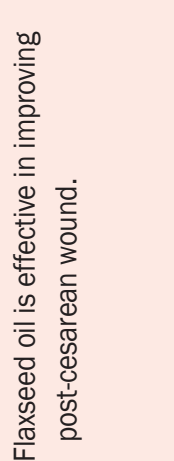 & 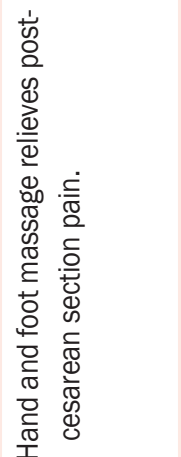 & 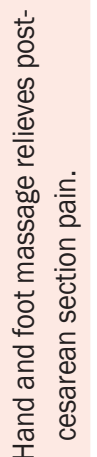 & 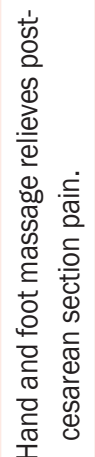 & 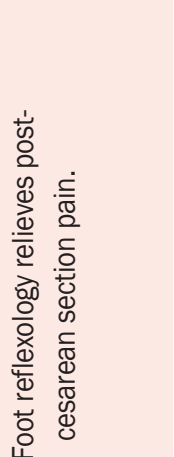 & 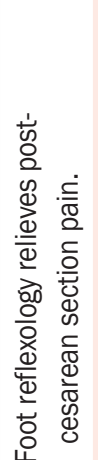 & 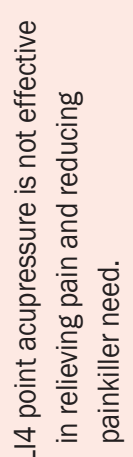 & 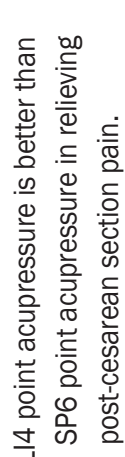 \\
\hline 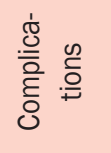 & 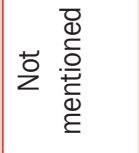 & io & 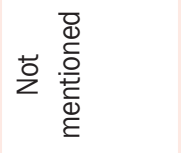 & 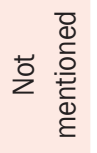 & 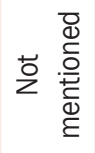 & 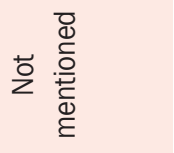 & 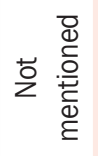 & 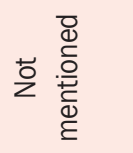 & 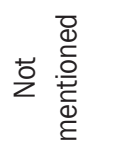 \\
\hline $\bar{\circ}$ & 吉 & 岑 & $\stackrel{0}{5}$ & $\stackrel{0}{5}$ & $\stackrel{\infty}{\$}$ & $\stackrel{0}{5}$ & $\stackrel{0}{5}$ & $\stackrel{0}{\$}$ & $\stackrel{0}{\$}$ \\
\hline $\begin{array}{l}\frac{0}{0} \\
\frac{0}{00} \\
\overline{0} \\
\frac{0}{0} \\
0 \\
0\end{array}$ & 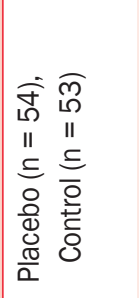 & 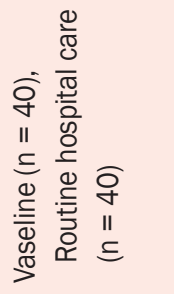 & 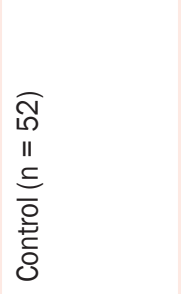 & 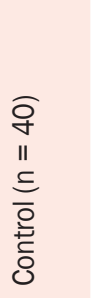 & 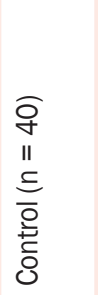 & 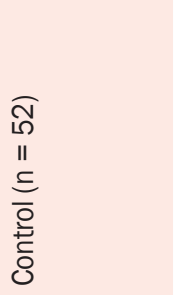 & $\begin{array}{l}\overline{0} \\
\stackrel{0}{0} \\
\text { Oे }\end{array}$ & 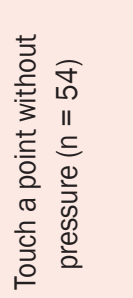 & 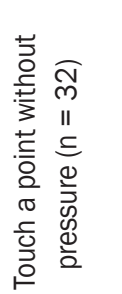 \\
\hline 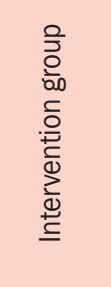 & 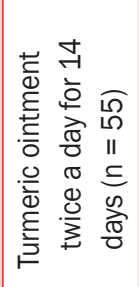 & 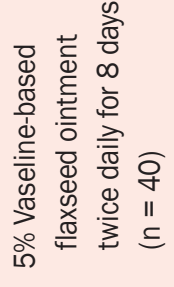 & 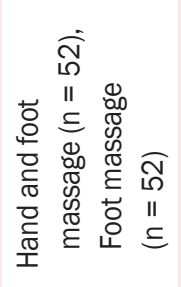 & 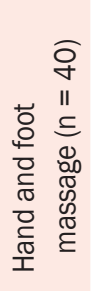 & 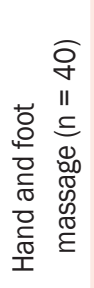 & 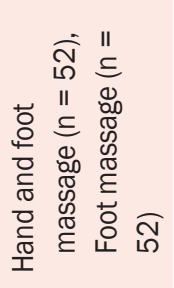 & 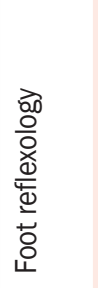 & 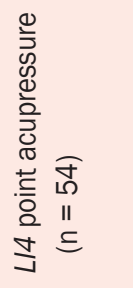 & 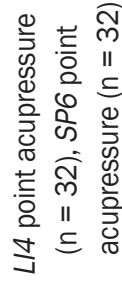 \\
\hline 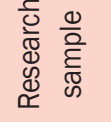 & $\begin{array}{l}\tilde{0} \\
\stackrel{1}{1} \\
\ddot{z}\end{array}$ & $\begin{array}{l}\stackrel{\overbrace{}}{7} \\
\ddot{z}\end{array}$ & $\begin{array}{l}\stackrel{\circ}{\stackrel{9}{ }} \\
\ddot{z}\end{array}$ & $\begin{array}{l}\infty \\
\searrow \\
\ddot{z}\end{array}$ & $\begin{array}{l}\infty \\
\searrow \\
\ddot{z}\end{array}$ & 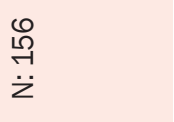 & $\begin{array}{l}\vec{\emptyset} \\
\ddot{z}\end{array}$ & $\begin{array}{l}\infty \\
\stackrel{\infty}{1} \\
\ddot{z}\end{array}$ & $\begin{array}{l}\mathscr{8} \\
\ddot{z}\end{array}$ \\
\hline $\begin{array}{l}\frac{0}{0} \\
\frac{0}{0} \\
\frac{00}{00} \\
\frac{0}{30}\end{array}$ & 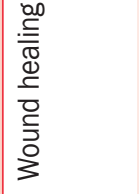 & 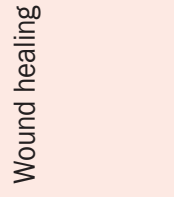 & 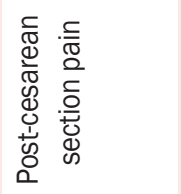 & 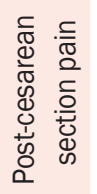 & 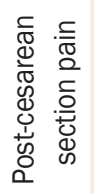 & 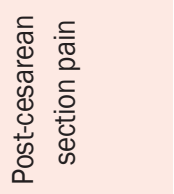 & 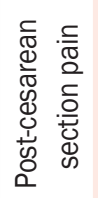 & 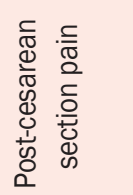 & 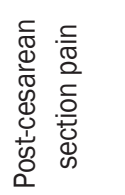 \\
\hline 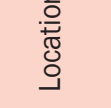 & $\stackrel{\stackrel{\complement}{\mathbb{0}}}{=}$ & $\stackrel{\stackrel{\mathbb{\widetilde { N }}}{=}}{=}$ & $\stackrel{\stackrel{ }{\mathbb{\varpi}}=}{=}$ & 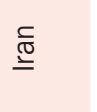 & $\stackrel{\stackrel{\complement}{\varpi}}{=}$ & $\stackrel{\frac{\pi}{\underline{\pi}}}{=}$ & 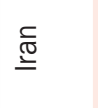 & $\stackrel{\mathbb{\widetilde { \varpi }}}{=}$ & $\stackrel{\underline{\underline{\pi}}}{\underline{\underline{\pi}}}$ \\
\hline 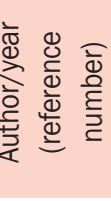 & 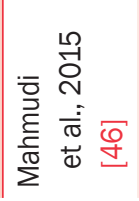 & 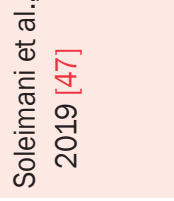 & 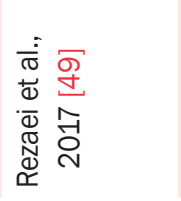 & 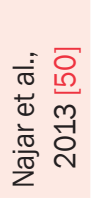 & 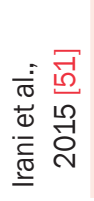 & 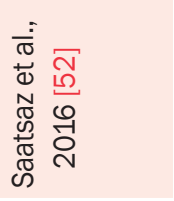 & 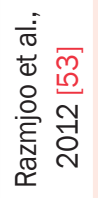 & 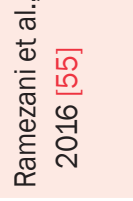 & 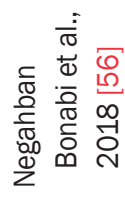 \\
\hline
\end{tabular}


lation (TENS) unit and inhalation of 3 drops of placebo, the intervention group used the TENS unit (100-150 Hz excitation for 30 minutes) and inhalation of 3 drops of placebo, and lavender essential oil group used deactivated TENS unit and inhalation of 3 drops of $10 \%$ lavender essential oil. The pain levels were measured at 4, 8, and $12 \mathrm{~h}$ postoperatively. Levels of pain reduction between Lavender and TENS unit groups were higher than control group. In addition, this difference was significant compared to Lavender essential oil and TENS unit groups, so that the use of TENS unit reduced pain to a higher level $(\mathrm{p}<0.001)$ [17].

Najafi et al. (2016) divided the study units randomly into two groups of inhalations of two drops of lavender essential oil and inhalation of placebo (two drops of normal saline). The pain intensity, before and after the intervention, was measured. The pain intensity in patients treated with lavender essential oil was significantly lower than in the placebo group $(\mathrm{p}<0.001)$ [18].

Olapour et al. (2013) used inhalation aromatherapy using lavender essential oil (for 5 minutes) in the intervention group and similarly used placebo in the control group; 4, 8 and 12 hours later, the pain score was measured using the VAS. The Lavender group reported less postoperative pain at 4 hours ( $p$ $=0.008), 8$ hours $(\mathrm{p}=0.024)$, and 12 hours $(\mathrm{p}=0.011)$ after the intervention compared with the placebo group [19].

\section{Hypericum perforatum}

Numerous bioactivities of Hypericum perforatum was described in the pharmacological studies other than the antidepressant activity, including wound-healing, antifungal, anti-inflammatory, anti- mycobacterial [20]. In a study of Samadi et al. (2010), participants were randomly divided into three groups; 24 hours after the cesarean section, the intervention group received $H$. perforatum ointment and the placebo group received placebo ointment three times daily for 16 days. The control group received no intervention. They evaluated post-cesarean wound at 10 days after cesarean section and measured pain levels at 40 days after cesarean section. There were significant differences in wound healing on the 10th day $(\mathrm{p}<0.005)$ and 40th day ( $\mathrm{p}<0.0001)$ postpartum between treatment group with placebo and control groups. However, the placebo group had no differences in wound healing $(\mathrm{p}=0.93)$ with the control group. In addition, A lower pain score was observed on the 40th day post cesarean in the treatment group $(\mathrm{p}<0.0001)$ [21].

\section{Calendula}

C. Officinalis is an annual herb belonging to Asteraceae. It contains different types of compounds including triterpenoids, saponins, coumarines, and flavonoids. In traditional medicine, it has been used for the treatment of wound healing and jaundice, and considered an anti-spasmodic $[22,23]$. Lavagna et al. (2001) assigned the study participants in two groups of topical combination of $70 \%$ Hypericum $+30 \%$ Calendula extract and Wheat germ ointment and asked to continue their treatment twice daily for 16 days. The treatment of episiotomy incision with Hypericum-Calendula mixture reduced the area of incision by $37.6 \pm 9.9 \%$ versus $15.83 \pm 4.64 \%$ in the control group [24].

\section{Honey}

Honey has been used for the treatment of various disorders including burns and chronic wounds as a traditional medicine for centuries by different cultures [25]. In a study of Nikpour et al. (2014), mothers were given similar gels with a specific code in both intervention (honey gel 25\%) and control groups (similar free-honey gel) twice daily for 14 days. Redness, edema and hematoma in the drug group were significantly lower on the 7 th $(\mathrm{p}=0.008)$ and 14 th $(\mathrm{p}=0.002)$ days [26].

Similarly, Shirvani et al. (2013) randomly divided the subjects into three groups of intervention (honey gel), placebo and control (no intervention). The mothers were asked to apply the gel twice a day for 14 days on the post-cesarean wound site and allow it to remain in site for 15 minutes. The pain intensity was measured on days 7 and 14 after cesarean section. The results showed that there was a significant difference between the three groups in pain intensity at days 7 and 14 postpartum $(\mathrm{p}<0.05)$ [27].

Heidari et al. (2013) divided the subjects randomly into three intervention groups (honey gel), placebo and control (no intervention). Mothers were asked to apply the drug on the postcesarean wound site twice daily for 16 days. Results showed no significant difference in pain intensity at 24 hours, 10 days and 40 days after cesarean section ( $\mathrm{p}<0.05)$. There was no statistically significant difference in the mean REEDA score at 10 days after cesarean section between Three groups ( $p>0.05)$. The mean REEDA score at 40 days after cesarean section showed a significant statistical difference between placebo and control groups, honey and control groups, but no significant difference 
was observed between honey and placebo groups $(p=0.76)$ [28].

\section{Anethum graveolens}

Anethum graveolens (Dill), from Apiaceae family, is a traditional herb that has various medical indications worldwide. its seeds have 3-3.5\% essential oil and are used for treatment of stomach illnesses, food digestion, stopping hiccup, flowing of milk in nursing mothers, relieving of pain and as anticonvulsant and antivomiting [29]. In a study of Shakeri et al. (2017), the intervention group received $10 \%$ Dill seed essential oil at 60 minutes and 30 minutes before spinal anesthesia and then at 30 minutes, 60 minutes and 120 minutes after spinal anesthesia. The control group was also given placebo at the same intervals. The pain intensity was assessed at 4 and 12 hours after cesarean section. There was a significant difference in the pain intensity between the two groups $(\mathrm{p}<0.01)$ [30].

In the study of Fazel et al. (2017), the intervention group received 40 drops of oral dill essential oil every 20 minutes up to one hour (three times) and the placebo group received no dill essential oil. The pain intensity was assessed at the end of every 20 minutes. Although the severe intestinal pain level was significantly reduced in both groups, this decrease was three times greater in the dill group at 20 minutes after the third dose $(\mathrm{p}<$ $0.001)[31]$.

\section{Grape}

Grape seed extract is rich in powerful antioxidant compounds such as flavonoids and Polyphenol. Phenolic compounds helps preserve skin moisture and accelerates wound healing [32]. In a study of Soorgi et al. (2016), Group A received $2.5 \%$ grape seed ointment and Group B received 5\% grape seed ointment and Group C received placebo. Mothers were asked to apply $1 \mathrm{~g}$ of ointment on the post-cesarean wound site every 12 hours. The wound site was evaluated at 6 and 14 days after the intervention, which showed a statistically significant difference between the three groups $(\mathrm{p}=0.02)$ [33].

\section{Salvia officinalis}

Salvia officinalis (Common sage) belongs to the family of labiatae whose essential oil is widely used in the perfume, food and pharmaceutical industries due to its antioxidant, antispas- modic, antiseptic, anti-inflammatory, antibiotic and sedative properties [34].

\section{Orange blossom}

The flowers of this plant are used in the treatment of neurological diseases such as seizures and neurasthenia. In addition, it is known as a sedative, hypnotic drug, appetizer and heart palpitation lifter [35]. In the study of Sharifipour et al. (2017), the subjects were randomly divided into three groups: Salvia officinalis, orange blossom and control. The intervention groups inhaled three drops of the essential oil for 5 minutes immediately, 4 hours, 8 hours and 12 hours after the onset of pain, and then pain scores were assessed 30 minutes after each intervention. The control group performed aromatherapy with normal saline. The mean pain was significantly decreased in the intervention group compared to the control group in all four stages ( $p<0.001)$, but there was no significant difference between the orange blossom and Salvia officinalis groups $(p>0.05)$ [36].

\section{Aloe vera}

Aloe vera (family Liliaceae) is from the group of flowering plants. In previous studies, many pharmacological properties of Aloe vera have been demonstrated such as the burn wound healing, anti-oxidant, anti-microbial, anti-viral, anti-ulcer [37, 38]. In a study of Molazem et al. (2014), the post-cesarean wound in the intervention group was coated with Aloe Vera gel and then dressed. In the control group, dressing was done using dry gauze alone. The wound healing was assessed at 24 hours and 8 days postoperatively. The results showed a significant difference in the REEDA score at 24 hours after surgery between the two groups $(p=0.003)$ but this difference was not significant after 8 days $(\mathrm{p}=0.283)$ [39].

Schmidt et al. (1991) asked the intervention group to cover the wound site with Aloe Vera gel after each dressing change. The routine dressing was used in the control group, and examination was performed daily. The duration of healing was $53 \pm$ 24 days in the control group and $83 \pm 28$ days in the intervention group, and this difference was statistically significant $(\mathrm{p}=$ 0.003) [40].

\section{Rosa damascena}

Rosa damascena, as a herbal medicine, has antitussive, re- 
laxant, antioxidant, hypnotic, antibacterial and anti-diabetic effects. In addition, the Rosa essence has anti-spasmodic and anti-inflammatory effects which lead to reduced pain [41]. Gharabaghi et al. (2011) randomly assigned the subjects into two intervention (400 capsules of R. damascena extract) and placebo (starch) groups. Then, two capsules along with $30 \mathrm{ml}$ of water were administered to the research units in the operating room 15 minutes before anesthesia. The pain intensity was assessed after transfer to ward at 3, 6, 12 and 24 hours. There was a statistically significant difference in the pain intensity between the two groups at the time points of examination $(p=0.001)$ [42].

\section{Chamomile}

Chamomile has anti-inflammatory, antibacterial and antifungal effect and topically used for treating skin inflammation, hemorrhoids, ulcers of the leg, and cracked nipples. It also has an effective role in reducing the pain and repairing damaged tissues [43]. Najafi et al. (2017) evaluated the effect of chamomile extract on post-cesarean section pain. Six hours after the cesarean section, inhalation of two drops of chamomile essential oil was used in the intervention group, and inhalation of two drops of normal saline was used as placebo in the control group. The pain was re-measured after 15 minutes. The pain intensity in the intervention group was significantly lower than in the control group $(\mathrm{p}<0.001)$ [44].

\section{Turmeric}

Turmeric is known as Auruk-e-Sufr. This spice is obtained from the root of Curcuma longa $\mathrm{L}$ which is a member of ginger family. There are many recommendations in traditional medicine that suggest the use of turmeric as an antiseptic therapeutic agent is beneficial in treating the skin injuries and healing of wounds, as well as improving rash, and scabies [45]. Mahmudi et al. (2015) evaluated the efficacy of turmeric cream on postcesarean wound. Subjects were randomly divided into three groups of intervention (Turmeric) and placebo (Vaseline) and control (no intervention). The patients were instructed to apply the cream sufficiently to cover the suture area the day after surgery and not to dress the wound for 15 minutes and continue this procedure twice daily for 14 days. The wound healing was assessed on days 7 and 14 after cesarean section. According to the results, there was a statistically significant difference in the mean REEDA score between the intervention and placebo groups $(p=0.027)$ and between the intervention and control groups $(\mathrm{p}=0.003)$, but this difference was not significant between the control and placebo groups [46].

\section{Flaxseed}

Flaxseed oil contains essential fatty acids, and unsaturated fatty acids of omega-3 and omega-6, which have anti-inflammatory, antimicrobial and antioxidant effects. Soleimani et al. (2019) randomly assigned participants to three groups of flaxseed oil, placebo and control. According to the results, there was a statistically significant difference in cesarean section wound healing at days 4 and 8 between the flaxseed oil and placebo groups as well as between the flaxseed oil and control groups ( $p$ $<0.001$ ) [47].

\section{Therapeutical massage}

Massage is one of the oldest therapeutic methods. It can relax muscles, improved sleep and blood circulation and relief of muscular aches and pains [48].

Rezaei et al. (2017) assigned the research units randomly into three groups of hand and foot massage, foot massage and control. The pain intensity was measured 4 hours after receiving the last dose of diclofenac suppository. In the intervention group, in addition to routine care, hand and foot massage was performed without any special equipment. The massage was carried out in the forms of petrissage, kneading and friction. The duration of massage for each limb was 5 minutes. The pain intensity was measured immediately and 90 minutes after the end of the massage to determine the duration of the massage effect. The results showed a significant decrease in pain immediately and 90 minutes after the massage in the intervention groups ( $\mathrm{p}<0.001$ ), but not significantly between the two groups $(\mathrm{p}=0.98)$ [49].

In a study of Najar et al. (2013), hand and foot massage was performed without any special tools in the intervention group in addition to routine care. The massage was performed as petrissage, kneading and friction. The duration of massage was 5 minutes for each limb. The pain intensity was measured immediately and 90 minutes after the end of the massage to determine the duration of the massage effect. In the control group, the researcher was present on the patient's bed for 20 minutes, but no massage was given. Results showed a significant decrease 
in pain immediately and 90 minutes after massage in the intervention group $(\mathrm{p}<0.001)$ [50].

Irani et al. (2015) investigated the effect of hand and foot massage on post-cesarean pain. the pain intensity was measured four hours after surgery and then massage was applied in the intervention group. The massage was applied every 5 minutes for 20 minutes to the patient's limbs. In the control group, the researcher was present in the patients' bedside for 20 minutes but did not perform any massage. The pain intensity was measured immediately, 60 and 90 minutes after the end of the massage. The results showed a decrease in the pain intensity in the intervention group immediately, 60 and 90 minutes after the intervention compared to the control group ( $p<0.001$ ) [51].

Saatsaz et al. (2016) similarly examined the effect of massage on post-cesarean section pain and reported a significant reduction in pain immediately and 90 minutes after massage in the intervention groups $(\mathrm{p}<0.001)$ [52].

Razmjoo et al. (2012) evaluated the impact of foot reflexology on post-cesarean section pain. The reflexology (one session for 20 minutes on both legs) was performed for 10 minutes for the intervention group 2-3 hours postoperatively in addition to routine care and only routine postoperative care was provided for the control group. The pain intensity was measured 2 hours after intervention. The results showed a significant decrease in the intervention group $(\mathrm{p}=0.004)$ [53].

\section{Acupuncture}

Acupuncture treatment involves insertion of fine needles into different parts of the body to balance of energy in the body and the overall energy levels [54].

Ramezani et al. (2016) evaluated the effect of LI4 point acupressure on post-cesarean section pain. The intervention group experienced LI4 point acupressure for 10 seconds with 2 seconds rest for 20 minutes. The control group received a touch of point without pressure. According to the results, there was no significant difference in the pain intensity scores immediately, 60 and 120 minutes after intervention between groups $(\mathrm{p}<0.05)$ [55]. In a study of Negahban Bonabi et al. (2018), research units were randomly divided into three groups: LI4 point acupressure, SP6 point acupressure and control (without pressure). Intervention was performed at the pressure points bilaterally, 10 seconds of pressure and 2 seconds of rest for 20 minutes consecutively. The pain intensity was determined before, immediately and one hour after the intervention. The LI4 point acupressure significantly decreased the mean pain score ( $\mathrm{p}=$ 0.033 ) compared to control group, while the mean pain score did not differ significantly in the SP6 point acupressure group compared to the control and the LI4 point acupressure groups ( $\mathrm{p}$ $=0.428)[56]$.

\section{DISCUSSION}

This study was designed to review the efficacy of complementary medicine on pain relief and accelerated wound healing after cesarean section. In three studies, the lavender essential oil had a greater effect in reducing the severity of post-cesarean section pain than placebo. Linalool and Linalyl acetate present in this plant are able to stimulate the parasympathetic nervous system and Linalyl acetate has a narcotic effect and Linalool in lavender acts as a sedative [57]. In a study of Ebrahimi Houshyar et al. (2015), the difference in pain level between two methods of TENS unit and aromatherapy with lavender essential oil in patients after cesarean section was significant in all three stages; the TENS unit group experienced less pain than lavender essential oil group, which may indicate that the TENS unit is more effective in reducing postoperative pain than in the lavender essential oil. Due to the absence of another study on the effect of the TENS unit on the relief of post-cesarean section pain, further studies are required to confirm these findings [17]. Three clinical trials were conducted to investigate the effect of honey on wound healing and pain relief after cesarean section. In a study of Nickpour et al. (2014), 25\% honey gel accelerated wound healing after cesarean section [26]. In a study of Shirvani et al. (2013), 25\% honey gel was more effective in relieving pain and reducing painkiller need than placebo [27], while Heidari et al. (2013) reported that the honey was ineffective in reducing pain and healing wound after cesarean section [28]. This difference in the results is justified by the difference in the time of intervention, the time of pain intensity measurement and the composition of honey gel. Two studies were found in the field of dill, the results of which showed the effect of dill essential oil on reducing post-cesarean section pain. Studies with a stronger methodology are recommended, given the limited studies available on the effect of dill on cesarean section pain. Molazem et al. (2014) reported the efficacy of Aloe Vera gel in wound healing after cesarean section [39]. In a study of Schmidt et al. (1991), using Aloe Vera gel had significant delay in wound healing compared to the control group [40]. Due to the limited study in this area, further studies are needed to con- 
firm or reject the effect of Aloe Vera. Four studies demonstrated the effect of hand and foot massage on reducing post-cesarean section pain. Pain receptors are generally located beneath the skin and deep tissues of the limbs, so it is reasonable for hand and foot massage to be effective in reducing pain. The results of studies evaluating the effects of Mentha piperita, Cuminum, calendula, Hypericum perforatum, grape seed, orange blossom, Aloe Vera, Rosa, chamomile, reflexology, acupressure indicate their positive efficacy in pain relief and prevention and treatment of post-cesarean wound. Given the limited scope of each study and the lack of definitive conclusions, further research in this area may be helpful.

\section{COCLUSION}

Evidence indicates that most medicinal plants are effective in pain relief and wound healing after the cesarean section. Further studies are recommended to obtain more accurate evidence because of the limited number of articles on most plants. Hand and foot massage is one of the effective strategies to reduce post-cesarean section pain, which can be helpful as an effective nursing intervention in postoperative pain management and control.

\section{ACKNOWLEDGMENT}

We would like to thank the Deputy of Research at Mashhad University of Medical Sciences for funding the current project. The present article is the result of a research project approved by Mashhad University of Medical Sciences, with the code of 981678 and has been approved with the ethical identification of IR.MUMS.NURSE.RES.1399.039.

\section{CONFLICT OF INTEREST}

The authors declare no conflict of interest in the publication of this article.

\section{AUTHORS' CONTRIBUTIONS}

M.M., A.N.,VR.A. and N.Sh. contributed to the study design, analysis and interpreting of data. M.M. and A.N. drafted the manuscript. M.M., A.N., VR.A. and N.Sh. revised the manuscript critically and approved the final manuscript.

\section{AVAILABILITY OF DATA AND MATERIALS}

The datasets generated and analyzed during the current study will be available on reasonable request.

\section{ORCID}

Azin Niazi, https://orcid.org/0000-0001-6586-2769

Maryam Moradi, https://orcid.org/0000-0002-9084-8907

Vahid Reza Askari, https://orcid.org/0000-0001-9268-6270

Neda Sharifi, https://orcid.org/0000-0002-7858-5948

\section{REFERENCES}

1. CORONIS Collaborative Group, Abalos E, Addo V, Brocklehurst P, El Sheikh M, Farrell B, et al. Caesarean section surgical techniques (CORONIS): a fractional, factorial, unmasked, randomised controlled trial. Lancet. 2013;382(9888):234-48.

2. Basha SL, Rochon ML, Quiñones JN, Coassolo KM, Rust OA, Smulian JC. Randomized controlled trial of wound complication rates of subcuticular suture vs staples for skin closure at cesarean delivery. Am J Obstet Gynecol. 2010;203(3):285.e1-8.

3. Chanif C, Petpichetchian W, Chongchareon W. Does foot massage relieve acute postoperative pain? A literature review. Nurs Media J Nurs. 2013;3(1):483-97.

4. Chanif. The effect of food massage on acute postoperative pain in Indonesian patients after abdominal surgery [master's thesis]. [Songkhla]: Prince of Songkla University; 2012. 142 p.

5. Niazi A, Yousefzadeh S, Rakhshandeh H, Esmaeili H. [Comparison of purslane cream and lanolin on nipple pain among breastfeeding women: a randomized clinical trial]. Iran J Obstet Gynecol Infertil. 2018;20(12):77-85. Persian.

6. Niazi A, Yousefzadeh S, Rakhshandeh H, Esmaeily H. The effect of nipple soreness treatment with purslane cream and lanolin on frequency and duration of breastfeeding in nursing mothers: a randomized clinical trial. J Midwifery Reprod Health. 2019; $7(1): 1534-42$.

7. Sepehrirad M, Bahrami H, Noras M. [The role of complementary medicine in control of premenstrual syndrome evidence based (Regular Review Study)]. Iran J Obstet Gynecol Infertil. 2016;19(24):11-22. Persian.

8. Nahas R, Sheikh O. Complementary and alternative medicine for the treatment of major depressive disorder. Can Fam Physician. 2011;57(6):659-63.

9. Page MJ, Moher D. Evaluations of the uptake and impact of the Preferred Reporting Items for Systematic reviews and MetaAnalyses (PRISMA) Statement and extensions: a scoping review. 
Syst Rev. 2017;6(1):263.

10. Jadad AR, Moore RA, Carroll D, Jenkinson C, Reynolds D, Gavaghan DJ, et al. Assessing the quality of reports of randomized clinical trials: is blinding necessary? Control Clin Trials. 1996;17(1):1-12.

11. Golestannejad Z, Gavanji S, Mohammadi E, Motamedi A, Bahrani $\mathrm{M}$, Rezaei $\mathrm{F}$, et al. Comparison of antibacterial activity of essential oils of Foeniculum vulgare Mill, Mentha arvensis and Mentha piperita against Streptococcus mutans. Adv Herbal Med. 2017;3(1):3-13.

12. Fazel N, Tafazoli M, Ramezani M, Esmaili H. The effect of supermint oil on the flatulence intensity after cesarean section. J Ardabil Univ Med Sci. 2004;4(4):41-6.

13. Johri RK. Cuminum cyminum and Carum carvi: an update. Pharmacogn Rev. 2011;5(9):63-72.

14. Fazel N, Esmaeili HA. [The effect of cumin oil on pain severity after cesarean section]. Iran J Obstet Gynecol Infertil. 2008;11(4):23-9. Persian.

15. Nikjou R, Kazemzadeh R, Rostamnegad M, Moshfegi S, Karimollahi M, Salehi $\mathrm{H}$. The effect of lavender aromatherapy on the pain severity of primary dysmenorrhea: a triple-blind randomized clinical trial. Ann Med Health Sci Res. 2016;6(4):211-5.

16. Sobhani A, Sharmi H. Effect of lavender oil on pain relief after cesarean section. J Gilan Med Univ. 2002;16:80-6.

17. Ebrahimi Houshyar A, Hosein Rezaie H, Jahani Y, Kazemi M, Monfared S. [Comparison of two methods of aromatherapy with lavender essence and Transcutaneous Electrical Nerve Stimulation (TENS) on cesarean postoperative pain]. Iran J Obstet Gynecol Infertil. 2015;18(146):6-12. Persian.

18. Najafi B, Fariba F, Daem R, Ghaderi L, Seidi J. The effect of Lavender Essence on pain severity after cesarean section under spinal anesthesia. J Chem Pharm Sci. 2016;7:66-9.

19. Olapour A, Behaeen K, Akhondzadeh R, Soltani F, Al Sadat Razavi F, Bekhradi R. The effect of inhalation of aromatherapy blend containing lavender essential oil on cesarean postoperative pain. Anesth Pain Med. 2013;3(1):203-7.

20. Niazi A, Moradi M. Sexual satisfaction and function in postmenopausal women treated with herbal medicines: a review of clinical trials. Evid Based Care. 2019;9(2):7-16.

21. Samadi S, Khadivzadeh T, Emami A, Moosavi NS, Tafaghodi M, Behnam HR. The effect of Hypericum perforatum on the wound healing and scar of cesarean. J Altern Complement Med. 2010;16(1):113-7.

22. Parente LM, Lino Júnior Rde S, Tresvenzol LM, Vinaud MC, de Paula JR, Paulo NM. Wound healing and anti-inflammatory effect in animal models of Calendula officinalis L. growing in Brazil. Evid Based Complement Alternat Med. 2012;2012:375671.

23. Eghdampour F, Jahdie F, Kheyrkhah M, Taghizadeh M,
Naghizadeh S, Hagani H. The impact of aloe vera and Calendula on perineal healing after episiotomy in primiparous women: a randomized clinical trial. J Caring Sci. 2013;2(4):279-86.

24. Lavagna SM, Secci D, Chimenti P, Bonsignore L, Ottaviani A, Bizzarri B. Efficacy of Hypericum and Calendula oils in the epithelial reconstruction of surgical wounds in childbirth with caesarean section. Farmaco. 2001;56(5-7):451-3.

25. Saikaly SK, Khachemoune A. Honey and wound healing: an update. Am J Clin Dermatol. 2017;18(2):237-51.

26. Nikpour M, Shirvani MA, Azadbakht M, Zanjani R, Mousavi E. The effect of honey gel on abdominal wound healing in cesarean section: a triple blind randomized clinical trial. Oman Med J. 2014;29(4):255-9.

27. Shirvani MA, Nikpour M, Azadbakht M, Banihosseini SZ, Zanjani R. The effect of honey gel on cesarean incision pain: a triple blind clinical trial. Afr J Pharm Pharmacol. 2013;7(1):19-24.

28. Heidari T, Roozbahani N, Farahani LA, Attarha M, Torkestani NA, Jamilian M, et al. Does Iranian Astragalus gossypinus honey assist in healing caesarean wounds and scars? Eur J Integr Med. 2013;5(3):226-33.

29. Heidarifar R, Mehran N, Heidari A, Tehran HA, Koohbor M, Mansourabad MK. Effect of Dill (Anethum graveolens) on the severity of primary dysmenorrhea in compared with mefenamic acid: a randomized, double-blind trial. J Res Med Sci. 2014;19(4):326-30.

30. Shakeri Hosseinabad S, Shabanian G, Shabanian S, Rafiean M, Kheiri S, Lorigooini Z, et al. Evaluating the effect of Dill (Anethum graveolens L.) seed essence on pain and vital sign of cesarean delivery with spinal anesthesia. J Ardabil Univ Med Sci. 2017;17(3):311-23.

31. Fazel N, Pejhan A, Taghizadeh M, Tabarraei Y, Sharifi N. Effects of Anethum graveolens L. (Dill) essential oil on the intensity of retained intestinal gas, flatulence and pain after cesarean section: a randomized, double-blind placebo-controlled trial. J Herbal Med. 2017;8:8-13.

32. Hemmati AA, Foroozan M, Houshmand G, Moosavi ZB, Bahadoram M, Maram NS. The topical effect of grape seed extract $2 \%$ cream on surgery wound healing. Glob J Health Sci. 2014;7(3):52-8.

33. Soorgi S, Izadpanah AM, Sharifzadeh GR, Torshizi M, Khazaye Z, Hasanpour M. The effects of grape seed extract ointment on approximation of cesarean section wound. Mod Care J. 2016;13(1):e8849.

34. Abrosh Z, Rezai M, Ashrafi F. Effect of antibacterial activity of Salvia officinalis essence. J Med Aromat Plants. 2004;20(4):45768.

35. L M Lopes C, Gonçalves e Sá C, de Almeida AA, da Costa JP, Marques TH, Feitosa CM, et al. Sedative, anxiolytic and antide- 
pressant activities of Citrus limon (Burn) essential oil in mice. Pharmazie. 2011;66(8):623-7.

36. Sharifipour F, Mirmohammad Ali M, Hashemzadeh M. [Comparison of the effect of Citrus arantium and Salvia officinalis aroma on post-cesarean section pain]. Iran J Obstet Gynecol Infertil. 2017;20(2):41-9. Persian.

37. Liu LY, Chen XD, Wu BY, Jiang Q. [Influence of Aloe polysaccharide on proliferation and hyaluronic acid and hydroxyproline secretion of human fibroblasts in vitro]. Zhong Xi Yi Jie He Xue Bao. 2010;8(3):256-62. Chinese.

38. Chantarawaratit P, Sangvanich P, Banlunara W, Soontornvipart K, Thunyakitpisal P. Acemannan sponges stimulate alveolar bone, cementum and periodontal ligament regeneration in a canine class II furcation defect model. J Periodontal Res. 2014; 49(2):164-78.

39. Molazem Z, Mohseni F, Younesi M, Keshavarzi S. Aloe vera gel and cesarean wound healing; a randomized controlled clinical trial. Glob J Health Sci. 2014;7(1):203-9.

40. Schmidt JM, Greenspoon JS. Aloe vera dermal wound gel is associated with a delay in wound healing. Obstet Gynecol. 1991; 78(1):115-7.

41. Hamdamian S, Nazarpour S, Simbar M, Hajian S, Mojab F, Talebi A. Effects of aromatherapy with Rosa damascena on nulliparous women's pain and anxiety of labor during first stage of labor. J Integr Med. 2018;16(2):120-5.

42. Gharabaghi PM, Tabatabei F, Fard SA, Sayyah-Melli M, Ouladesahebmadarek E, Del Azar A, et al. Evaluation of the effect of preemptive administration of Rosa damascena extract on postoperative pain in elective cesarean sections. Afr J Pharm Pharmacol. 2011;5(16):1950-5.

43. Aradmehr M, Azhari S, Ahmadi S, Azmoude E. The effect of chamomile cream on episiotomy pain in Primiparous women: a randomized clinical trial. J Caring Sci. 2017;6(1):19-28.

44. Najafi B, Mojab F, Ghaderi L, Farhadifar F, Roshani D, Seidi J. The effect of chamomile flower essence on pain severity after elective caesarean section under spinal anaesthesia: a randomized clinical trial. J Clin Diagn Res. 2017;11(11):UC01-4.

45. Ghorbani Z, Khadem E. Therapeutic applications of turmeric and its principle constituent curcumin in wound healing and skin regeneration from the perspective of conventional medicine and Iranian Traditional Medicine (ITM). J Med Plants. 2017;
16(64):12-21.

46. Mahmudi G, Nikpour M, Azadbackt M, Zanjani R, Jahani MA, Aghamohammadi A, et al. The impact of turmeric cream on healing of Caesarean scar. West Indian Med J. 2015;64(4):400-6.

47. Soleimani M, Yousefzadeh S, Salari R, Vahed SHM, Mazloum SR. [The effects of flaxseed ointment on cesarean wound healing: randomized clinical trial]. Iran J Obstet Gynecol Infertil. 2019;22(9):64-71. Persian.

48. Will JS, Bury DC, Miller J. Mechanical low back pain. Am Fam Physician. 2018;98(7):421-8.

49. Rezaei R, Saatsaz S, Alipour A, Beheshti Z. [Massage-therapy and post cesarean pain control]. Iran J Obstet Gynecol Infertil. 2017;20(4):34-43. Persian.

50. Najar S, Akbari M, Abbaspoor Z, Haghighizadeh M. The effect of hand and foot massage on pain intensity after caesarean. Sci J Ilam Univ Med Sci. 2013;20(4):39-48.

51. Irani M, Kordi M, Tara F, Bahrami HR, Shariati Nejad K. The effect of hand and foot massage on post-cesarean pain and anxiety. J Midwifery Reprod Health. 2015;3(4):465-71.

52. Saatsaz S, Rezaei R, Alipour A, Beheshti Z. Massage as adjuvant therapy in the management of post-cesarean pain and anxiety: a randomized clinical trial. Complement Ther Clin Pract. 2016;24:92-8.

53. Razmjoo N, Hafizi lotfabadi L, Yousefi F, Esmaeeli H, Azizi H, Lotfalizadeh M. [Effect of foot reflexology on pain and anxiety in women following elective cesarean section]. Iran J Obstet Gynecol Infertil. 2012;15(1):8-16. Persian.

54. Hamidzadeh A, Shahpourian F, Orak RJ, Montazeri AS, Khosravi A. Effects of LI4 acupressure on labor pain in the first stage of labor. J Midwifery Womens Health. 2012;57(2):133-8.

55. Ramezani S, Hamidzadeh A, Abdollahpour S, Khosravi A. Effects of LI4 acupressure on post-cesarean section pain. Int J Health Stud. 2016;2(2):23-6.

56. Negahban Bonabi T, Ansari Jaberi A, Esmaeilzadeh S, Hasanshahi Ravizi A. [Comparison of the effect of acupressure at LI4 and SP6 points on the intensity of post cesarean pain]. Iran J Obstet Gynecol Infertil. 2018;21(6):9-17. Persian.

57. Sheikhan F, Jahdi F, Khoei EM, Shamsalizadeh N, Sheikhan M, Haghani H. Episiotomy pain relief: use of Lavender oil essence in primiparous Iranian women. Complement Ther Clin Pract. 2012;18(1):66-70. 